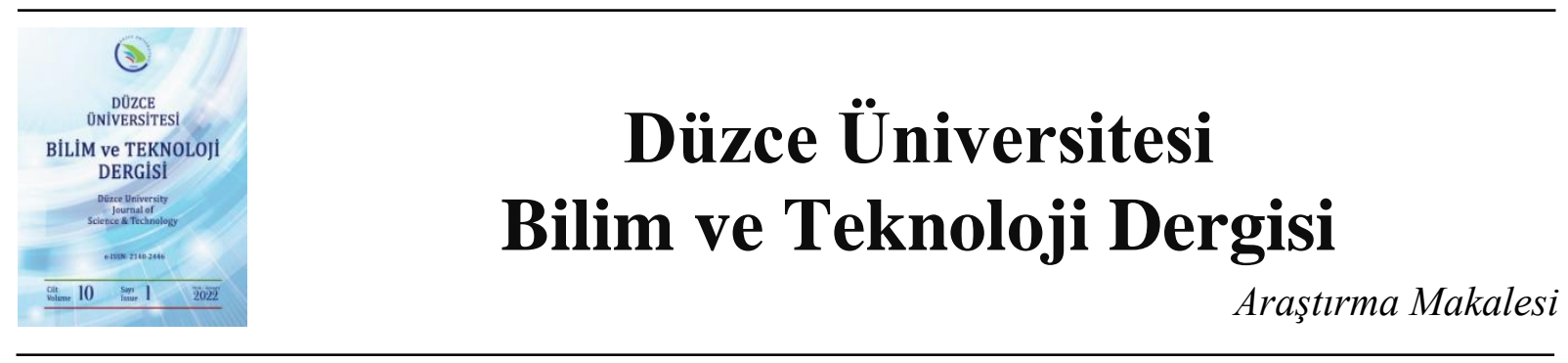

\title{
Kızılcasu (Kastamonu) Orman Planlama Birimi’nin Floristik Kompozisyonu, Hayat Formu ve Korotip Özellikleri
}

\author{
Mustafa KARAKÖSE ${ }^{\text {a,* }}$ \\ ${ }^{a}$ Bitkisel ve Hayvansal Üretim Bölümü, Espiye Meslek Yüksekokulu, Giresun Üniversitesi, Giresun, TÜRKIYE \\ * Sorumlu yazarın e-posta adresi: mustafa.karakose@giresun.edu.tr
}

DOI: 10.29130/dubited.926823

\begin{abstract}
$\underline{\mathrm{OZZ}}$
$\mathrm{Bu}$ çalışma 2008-2009 yılları arasında Kızılcasu Orman Planlama Birimi’nin florasını tespit etmek amacı ile yapılmıştır. Çalışma alanı Kastamonu ili A4 karesinde ve Avrupa-Sibirya floristik bölgesi içerisinde yer almaktadır. Çalışma sonucunda 64 familyaya ait 233 vasküler bitki taksonu tespit edilmiştir. Tespit edilen bitki taksonlarından 3'ü Pteridophyta bölümüne, 230'u ise Magnoliophyta bölümüne aittir. Magnoliophyta bölümüne ait bitki taksonlarından $5(\% 2,1)$ 'i Pinidae alt-sınıfına, $225(\% 96,6)$ 'i ise Magnoliidae alt-sınıfı içerisinde kalmaktadır. Çalışma alanında 8'i endemik ve 2'si nadir bitki taksonu tespit edilmiş olup, endemizm oranı ise \%3,4 olarak hesaplanmıştır. Takson zenginliği dikkate alındığında en zengin familya Asteraceae (26 bitki taksonu)'dir. Bu familyayı sırası ile Rosaceae, Lamiaceae ve Fabaceae takip etmektedir. Çalışma alanında saptanan 233 taksonun 126'sının (\%54,1) fitocoğrafik bölgesi belirlenebilmiştir. Bu taksonlardan 82'si $(\% 35,2)$ Avrupa-Sibirya, 26 (\%11,2)'s1 Öksin, 6 (\%2,6)'s1 Akdeniz, $6(\% 2,6)$ 's1 İran-Turan, 3 (\%1,3)' ü Hirkan-Öksin, 2 $(\% 0,9)$ 'si Doğu Akdeniz ve $1(\% 0,4)$ 'i ise Öksin (Dağ) elementidir. Kızılcasu'da Hemicryptophyte karakterde 115 (\%50) taksonların dominantlığı bulunmaktadır. Bu hayat formunu 59 (\%25,3) taksonla Phanerophyte ve 24 $(\% 10,3)$ taksonla da Cryptophyte karaktere sahip taksonlar takip etmektedir. Bu çalışma sonucunda nadir bir takson olan Leonurus cardiaca L. için yeni bir yayılış alanı tespit edilmiştir.
\end{abstract}

Anahtar Kelimeler: Bitkisel Biyoçeşitlilik, Endemik, Flora, Türkiye

\section{Floristic Composition, Life Form and Chorotype Features of Kiz1lcasu (Kastamonu) Forest Planning Unit}

\begin{abstract}
This study was carried out between 2008-2009 in order to determine the flora of Kizılcasu Forest Planning Unit. The study area is located in the A4 square of Kastamonu province and within the Euro-Siberian floristic region. As a result of the study, 233 vascular plant taxa belonging to 64 families were determined. 3 of the plant taxa identified belong to the Pteridophyta section and 230 to the Magnoliophyta section. Of the plant taxa belonging to the Magnoliophyta section, $5(2.1 \%)$ are within the Pinidae sub-class and 225 (96.6\%) are within the Magnoliidae sub-class. 8 of them are endemic and 2 of them are rare plant taxa in the study area, and the rate of endemism has been calculated as $3.4 \%$. Considering the richness of taxa, the richest family is Asteraceae (26 plant taxa). This family is followed by Rosaceae, Lamiaceae and Fabaceae, respectively. The phytogeographic regions of 126 taxa represented in the study area are as follows: Euro-Siberian $112(48.1 \%)$, Mediterranean 8 (3.4\%), and IranoTuranian 6 (2.6\%). Hemicryptophytes are dominant in Kizilcasu with $115(50 \%)$ taxa. This life form is followed by Phanerophytes with $59(25.3 \%)$ taxa and Cryptophytes with $24(10.3 \%)$ taxa. As a result of this study, a new distribution area for Leonurus cardiaca L., which is a rare taxon, has been determined.
\end{abstract}

Keywords: Plant Biodiversity, Endemic, Flora, Turkey 


\section{GIRIS}

Türkiye, sahip olduğu 4157'si endemik 12975 bitki taksonu [1-5] ile dünyada önemli biyolojik çeşitlilik merkezlerinden bir tanesidir. Bu zenginliğin kaynakları arasında farklı toprak tiplerine ve topografyaya sahip olması yanında üç farklı floristik coğrafyaya ev sahipliği yapması ve farklı mikro-makro iklim yapılarının hissedilmesi yer almaktadır [6]. Bu özellikler deniz seviyesinden yaklaşık 5500 m'ye kadar olan yükselti farklılığı ile çeşitli habitat yapılarının ortaya çıkmasına ve de biyolojik çeşitliliğin artmasına büyük katkı sağlamıştır [7].

Türkiye, farklı iklim koşulları altında üç farklı floristik bölgenin keşişim yerindedir. Akdeniz, İranTuran ve Avrupa-Sibirya floristik bölgelerinde bu iklim koşulları altında farklı topluluklar yaşam olanağı bulmakta ve her bir topluluğun kendine has karakteristikleri bulunmaktadır [8]. Avrupa-Sibirya floristik bölgesi, Türkiye'nin kuzeyinde Karadeniz bölgesinde Euxine (Öksin) provens ile temsil edilmektedir [9]. Öksin provens iklime bağlı farklı alt bölgelere ayrılmıştır [10]. Farklı araştırmacılar Öksin kesimi (Öksin ve Kolşik olarak) ikiye ayırmaktadır. Halbuki, bu durum hatalı olup [11], Kolşik sektör, Öksin provens içerisinde bir alt bölüm olarak kabul edilmektedir [6, 9]. İklim, bu oluşumda kendisini göstermektedir. Nitekim, Ordu-Melet ırmağının batısında yağış miktarı, doğusuna kıyasla, azalmaktadır. Batı Karadeniz, üç iklim (Akdeniz, okyanusal ve yarı-karasal) tipinin de etkisini gösterdiği bir alandır [12]. Bu etki ile birlikte gerek odunsu flora gerekse de otsu tabaka oldukça çeşitlilik arz etmektedir [13, 14].

Kastamonu ili de Batı Karadeniz bölgesinde yer alan önemli dağ silsilesi gruplarına ve bitkisel tür çeşitliliğine ev sahipliği yapmaktadır. Bu floristik çeşitliliği ortaya çıkarmak için fazla miktarda çalışma bulunmaktadır. Fakat bunlardan Karaköse ve Terzioğlu [15], Tuttu vd. [16], Özen vd. [17], Ketenoğlu ve Güney [18], Özbek ve Vural [19] çalışmaları haricindekiler şu hali ile rapor ya da lisansüstü çalışmalar olarak kalmışlardır.

$\mathrm{Bu}$ çalışma ile Kastamonu ili sınırları içerisinde yer alan Kızılcasu Orman Planlama Birimi’nin florası çıkartılmaya çalışılmıştır. Elde edilen veriler ilgili planlama biriminin ormancılık çalışmalarında ve yönetim planlarının oluşturulmasına katkı sağlayacaktır.

\section{MATERYAL VE METOT}

\section{A. ÇALIŞMA ALANININ COĞRAFİ KONUMU VE ÖZELLİKLERİ}

Kızılcasu Orman Planlama Birimi (OPB), mülki bakımdan Kastamonu ili, Şenpazar ilçesi sınırları içerisinde olup, idari bakımdan Kastamonu Orman Bölge Müdürlüğü, Cide Orman İşletme Müdürlüğü, Kızılcasu Orman İşletme Şefliği sorumluluğundadır. Planlama birimi, Greenwich başlangıç meridyenine göre: $33^{\circ} 13^{\prime} 55^{\prime \prime}-33^{\circ} 25^{\prime} 50^{\prime \prime}$ doğu boylamları ile ekvatora göre $41^{\circ} 46^{\prime} 23^{\prime \prime}-41^{\circ} 45^{\prime} 45^{\prime \prime}$ kuzey enlemleri arasındadır (Şekil 1). Kızılcasu OPB'nin merkezi olan Şenpazar ilçesi, karayolu ile bağlı olduğu Cide Orman İşletme Müdürlügünün bulunduğu Cide ilçesine $37 \mathrm{~km}$, Kastamonu iline ise 100 $\mathrm{km}$ mesafededir. Planlama birimi $300 \mathrm{~m}$ ile $1450 \mathrm{~m}$ yükseltiler arasındadır. Çalışma alanının kuzey ve güney hudutlarında yayvan sırtlar bulunmasına karşılık, arazi genelde oldukça sarp ve meyillidir. Kızılcasu Planlama Birimi, bitki coğrafyası yönünden Avrupa-Sibirya flora alanının Öksin provens ve A4 karesi içerisinde yer almaktadır [20]. Bununla birlikte, planlama birimi Batı Küre Dağları önemli bitki alanı içerisinde yer almaktadır [14].

Kızılcasu OPB, Batı Karadeniz bölgesinde yer almaktadır. Araştırma alanında, iklim özelliklerinin yükselti ve bakı farklarına göre incelenmesini sağlayacak uygun bir meteoroloji ağı mevcut değildir. Çalışma alanına en yakın olarak, uzun süreli gözlem ve ölçümlerin yapıldığı Cide (36 m.), Azdavay (800 m.), Kastamonu (800 m.) ve İnebolu (167 m.) meteoroloji istasyonları bulunmaktadır. Çalışma 
alanı bu dört meteoroloji istasyonunun kapsamı içerisinde kalmaktadır. Bu kapsamda iklim verileri incelendiğinde yıllık ortalama sicaklık değerleri Cide'de $14{ }^{\circ} \mathrm{C}$, Azdavay'da $8.4{ }^{\circ} \mathrm{C}$, Kastamonu'da 9.7 ${ }^{\circ} \mathrm{C}$ ve İnebolu'da ise $13{ }^{\circ} \mathrm{C}$ olarak belirlenmiştir. Kızılcasu OPB için ortalama yıllık yağış değerleri ise sirasiyla $1181 \mathrm{~mm}, 598.3 \mathrm{~mm}, 517 \mathrm{~mm}$ ve 1039.4 mm'dir. Cide, Azdavay, Kastamonu ve İnebolu verilerine göre yağış rejimleri sırasıyla KSYİ (okyanusal), KİSY (Doğu Akdeniz), IYYSK (yarı-karasal) ve SKIY (Sub-Akdeniz) olarak hesaplanmıştır [12]. Çalışma alanına yakın meteorolojik verilerin yorumlanması ile Cide ve İnebolu için yağışl1-kışı serin Akdeniz, Azdavay için az yağış11-kışı çok soğuk Akdeniz ve Kastamonu için ise yarı kurak-kışı çok soğuk Akdeniz karakterli iklim tiplerinin varlığı tespit edilmiştir $[12,21]$.

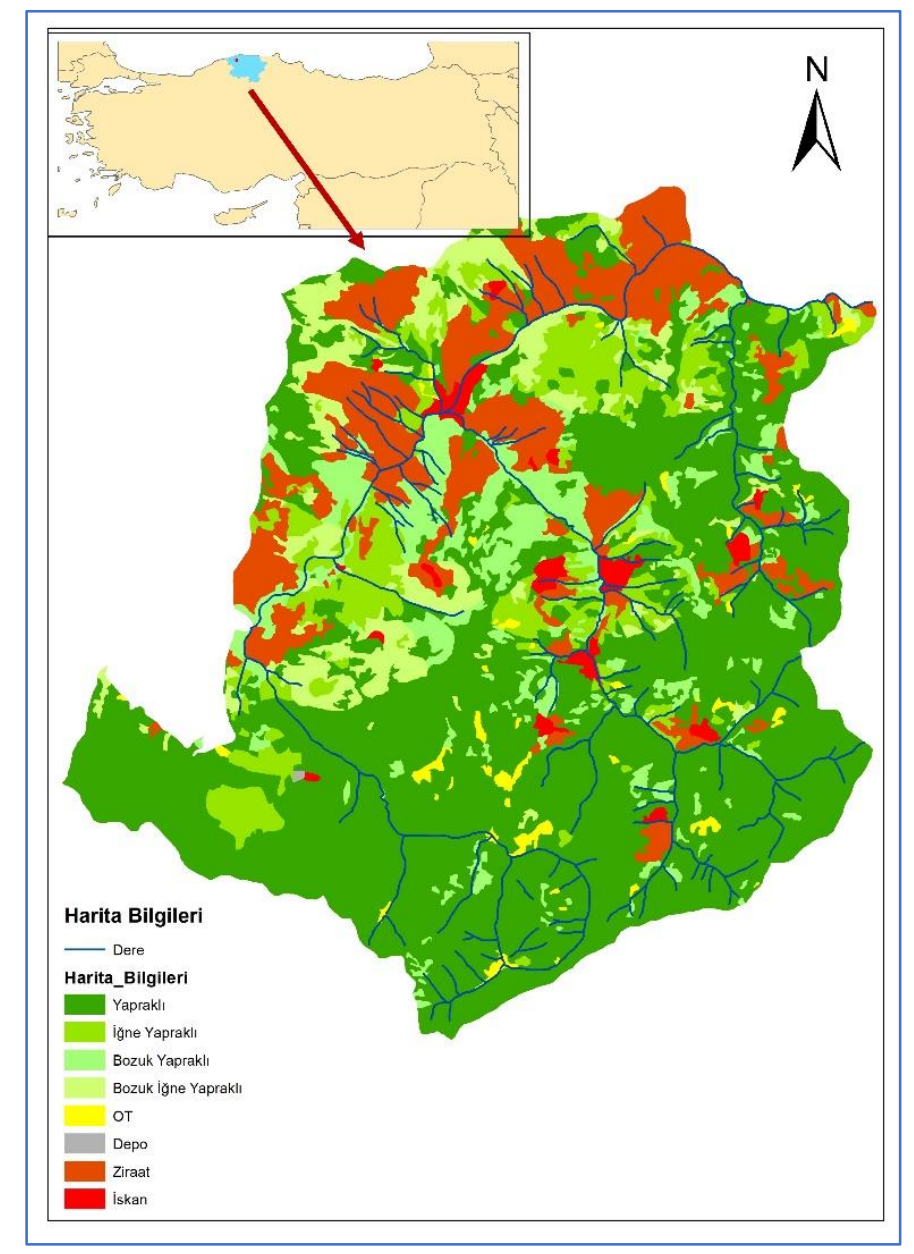

Şekil 1. Kızllcasu OPB 'nin lokasyonu

Kızılcasu OPB'nde, genel olarak orman ve çalı formasyonları yayılış yapmaktadır. Ekosistem çeşitliliğinin bir parçası olan bitki toplumları farklılaşması da alanda belirgin özelliğe sahiptir. Alanın vejetasyon tipleri ve her birinin belirgin bitkileri şunlardır: Orman vejetasyonu, bu vejetasyon tipinin asli ağaçları olarak Kazdağı Göknarı (Abies nordmanniana subsp. equi-trojani (Asc. \& Sint. ex Boiss.) Coode \& Cullen), Doğu Kayını (Fagus orientalis Lipsky), Karaçam (Pinus nigra subsp. pallasiana (Lamb.) Holmboe) ve Sarıçam (Pinus sylvestris var. hamata Steven) türlerinden oluşan ormanlar bu vejetasyon tipini oluşturur. Bu türler yükselti ve bakıya bağl olarak gerek saf gerekse karışı meşcereler kurmaktadırlar. Bu hâkim türlere ayrıca Adi Gürgen (Carpinus betulus L.), Bazı Akçaağaç (Acer heldreichii subsp. trautvetteri (Medw.) A.E.Murray, Acer platanoides L., Acer campestre L. subsp. campestre ve Acer hyrcanum Fisch. \& C.A.Mey. subsp. hyrcanum) türleri eşlik ederken, orman alt1 florasında (ara ve alt tabakada) da Mor Çiçekli Orman Gülü (Rhododendron ponticum L.), Sarı Çiçekli Orman Gülü (Rhododendron luteum Sweet), Karayemiş (Laurocerasus officinalis M.Roem.), Çoban Püskülü (Ilex colchica Pojark.) ve Likarpa (Vaccinium arctostaphylos L.) türleri yoğun populasyonlar 
halinde yayılmaktadır. Kimi alanlarda Kara Kavak (Populus nigra L. subsp. nigra) ve Sapsız Meşe (Quercus petraea subsp. iberica (Steven ex M.Bieb.) Krassiln.) hâkimiyetinde meşcereler yer almaktadır. Planlama birimi oldukça heterojen bir yapıya sahip olup, belirli bir zonlama yapmaya uygun değildir. Planlama Birimi Şenpazar'a yakın kısımlarda aşırı otlatma ve faydalanmalarla önemli ölçüde zarar görmüş ve alan kaybına uğramıştır. Bu tür alanlarda tek tek bireyler halinde Ahlat (Pyrus elaeagnifolia Pall. subsp. elaeagnifolia), Armut (Pyrus communis L. subsp. communis), Çakal Eriği (Prunus spinosa L.), Muşmula (Mespilus germanica L.), bireylerine rastlanmaktadır ki bu durumda alanda mevcut olan Yaban Hayatı için yeterli bir besin kaynağının varlığını göstermektedir. Nemli dere vejetasyonu, Araştırma alanında özellikle Şenpazar ilçesini ikiye bölen Şehribani Çayı boyunca yayılış gösteren Doğu Çınarı (Platanus orientalis L.) ile Ak Söğüt (Salix alba L. subsp. alba) ve Salman Köyü civarlarında bulunan İmamoğlu Deresi ve Koçal Çayı boyunca yayılış gösteren, Söğüt spp. (Salix alba, Salix elaeagnos Scop. ve Salix amplexicaulis Bory \& Chaub.) ve Kızılağaç (Alnus glutinosa (L.) Gaertn. subsp. glutinosa) hâkimiyetindeki vejetasyon tipidir. Çalı formasyonu, bu formasyon tipi ise alan içerisinde bulunan milli park dahilinde yayılışının büyük bir çoğunluğunu yapmaktadır. Odunsu türlerin çok dar alanda yoğun olarak bulunduğu bu tür alanlar adeta doğal bir arboretum niteliğindedir. Genel olarak yaprağını döken çalı ve ağaç̧̧k türlerinden oluşmuşsa da içerisinde Dağ Karaağacı (Ulmus glabra Huds.), Kafkas Ihlamuru (Tilia rubra subsp. caucasica (Rupr.) V.Engl.), Akçaağaç spp., Türk Fındığı (Corylus colurna L.), Kayacık (Ostrya carpinifolia Scop.), Dişbudak (Fraxinus excelsior L. subsp. excelsior) gibi ağaç türleri de yayılış yapmaktadır. Bu vejetasyon tipinde genel olarak; Patlangaç (Staphylea pinnata L.), Adi findık (Corylus avellana L. var. avellana), Papaz külahı (Euonymus latifolius Mill. subsp. latifolius), Adi şimşir (Buxus sempervirens L. subsp. sempervirens) türlerini görmek mümkündür.

\section{B. BİTKI ÖRNEKLERININ TOPLANMASI VE İNCELENMESI}

Bu floristik araştırma, 2008-2009 yılları içerisinde planlama biriminin florasının belirlenebilmesi için çeşitli vejetasyon dönemlerinde yöntemine uygun olarak toplanmış üzerinde çiçek, meyve, tomurcuk ve vejetatif organları taşıyan Pteridophyta ve Magnoliophyta bölümlerine ait bitki örnekleri toplanmıştır. Toplanan bitki örneklerinin teşhisleri KATO herbaryumunda (Karadeniz Teknik Üniversitesi Orman Fakültesi Herbaryumu) yapılmıştır. Teşhisleri tamamlanan materyaller Karadeniz Teknik Üniversitesi Orman Fakültesi Herbaryumu (KATO)'nda muhafaza altına alınmıştır. Arazi çalışmaları sırasında toplanan örneklerin bulunuş yeri, yetişme yeri özellikleri, yükselti ve toplanma tarihleri kaydedilmiştir. Teşhisleri sonucu saptanan Türkiye'nin taraf olduğu uluslararası sözleşmeler (CITES, IUCN, Bern) ile koruma altına alınmış bitki türleri de belirlenmiştir.

Herbaryum örneği haline getirilen taksonların teşhisinde temel eser olarak "Flora of Turkey and the East Aegean Islands" $[20,22,23]$ kullanılmıştır. Çalışma sonucu saptanan vasküler bitkilerin taksonomik birimlere göre listesi Pteridosperm Phylogeny Group PPG I [24]'ya, Gymnospermae; Christenhusz vd. [25]'e, Angiospermae taksonları ise Angiosperm Phylogeny Group (APG) IV, Chase vd. [26]'ya göre sistematik bir dizin halinde hazırlanmıştır. Teşhisleri yapılan bitki taksonlarının güncel durumları ve korotipleri Güner vd. [5]'ten yararlanılarak kontrol edilmiştir. Bitkilerin hayat formları ise Raunkiaer [27]'e göre düzenlenmiştir.

\section{KISALTMALAR VE SIMGELER}

Metin içerisinde kullanılan simge ve kısaltmalar şöyledir: Akd: Akdeniz; Avr-Sib: Avrupa-Sibirya; Bern: Berne Convention on the Conservation of European Wildlife and Natural Habitats, Ch: Chamaephyte, CITES: Convention on International Trade in Endangered Species of Wild Flora and Fauna, CR: Critically Endangered; D. Akd: Doğu Akdeniz; EN: Endangered; EUNIS: The European Nature Information System, H: Hemicryptophyte, ha: hektar, Hir-Öksin: Hirkan-Öksin; IUCN: International Union for the Conservation of Nature and Natural Resources; İr-Tur: İran-Turan; km: Kilometre; LC: Least Concern; m: metre; NT: Near Threatened, Ph: Phanerophyte, Th: Therophyte, VP: Vasküler Parazit, VU: Vulnerable. 


\section{BULGULAR}

Araştırma alanında, Eğreltiler (Pteridophyta) ve Tohumlu Bitkiler (Magnoliophyta) bölümleri dahilinde 64 familya ve 165 cinse ait toplam 233 bitki taksonu saptanmıştır (Tablo 1). Bunlardan Pteridophyta bölümü 3 takson ile \%1,3'lük, Magnoliophyta bölümü ise 230 taksonla \%98,7'lik orana sahiptir. Pteridophyta bölümü dahilinde 1 takson Equisetidae, 2 takson ise Polypodiidae alt-sinifları bünyesindedir. Magnoliophyta bölümü ise Pinidae [5 takson $(\% 2,1)]$ ve Magnoliidae [225 takson $(\% 96,6)]$ alt-sınıfları ile temsil edilmektedir. Planlama biriminde sinırları dahilinde tespit edilen 65 familyadan en fazla takson sayısına sahip olan familya 26 takson ile $(\% 11,2)$ Asteraceae (Compositae) olmuştur. Bu familyayı Rosaceae 23 taksonla $(\% 9,9)$, Lamiaceae 19 taksonla $(\% 8,2)$ ve Fabaceae 16 taksonla $(\% 6,8)$ takip etmektedir. Buna ek olarak, en zengin cins ise Campanula $(5-\% 3,3)$ olup, bu cinsin ardından Ranunculus (4- \%2), Galium (4- \%2), Salix (4-\%2), Salvia (4- \%2) ve Acer (4-\%2) cinsleri gelmektedir.

Kızılcasu OPB'nde tespit edilen 233 bitki taksonunun 126'sının $(\% 54,1)$ bitki coğrafya (koroloji) bölgesi belirlenmiştir. Bu taksonlardan 82'si (\%35,2) Avrupa-Sibirya, 26 (\%11,2)'s1 Öksin, $6(\% 2,6)$ 's1 Akdeniz, $6(\% 2,6)$ 'si İran-Turan, 3 (\%1,3)'ü Hirkan-Öksin, $2(\% 0,9)$ 'si Doğu Akdeniz ve $1(\% 0,4)$ 'i ise Öksin (Dağ) elementidir. Kozmopolitan ve çok bölgeli-bilinmeyen taksonların oranı ise \%45,9 (107 takson) olmuştur. Saptanan taksonların fitocoğrafik bölgelere göre oransal dağılımı Şekil 2'de verilmiştir. Planlama biriminde yayılış yapan bitki taksonlarının hayat formları spektrası Şekil 3'tedir. Şekil 3 'ten izlenildiği gibi Kızılcasu'da Hemicryptophyte karakterde 115 takson (\%50) ile dominantlı̆ bulunmaktadir. Hemikriptofitleri daha sonra sırası ile $59(\% 25,3)$ taksonla Phanerophyte, $24(\% 10,3)$ taksonla Cryptophyte, $17(\% 7,3)$ taksonla Therophyte, $16(\% 6,9)$ taksonla Chamaephyte ve $2(\% 0,9)$ taksonla da vaskuler parazitler takip etmektedirler (Şekil 3).

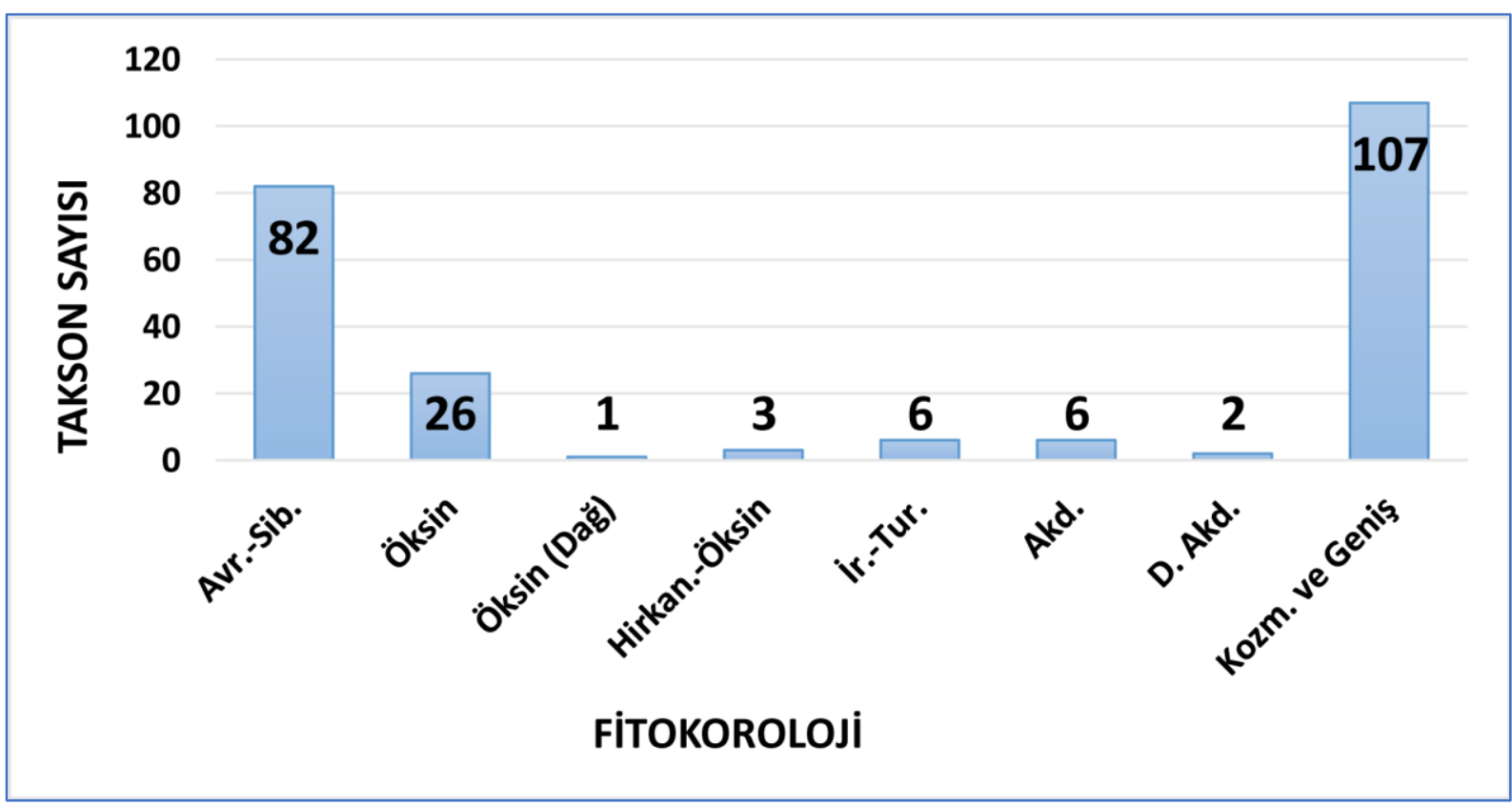

Şekil 2. Kuzılcasu OPB'nde tespit edilen taksonların korolojik dağgllımı

Çalışma alanında tespit edilen bitkilerin endemiklik veya ender olma ya da diğer koruma statüleri de incelenmiştir. Çalışma alanı içerisinde 8 endemik ve 2 nadir bitki taksonu tespit edilmiştir. Endemizm oranı ise \%3,4 olarak hesaplanmıştır. Alanda tespit edilen endemik bitkilerin IUCN kategorilerindeki durumları incelendiğinde, Kızılcasu OPB'nde, CR, EN ve NT kategorilerine ait bitki taksonuna rastlanmamıştır. 


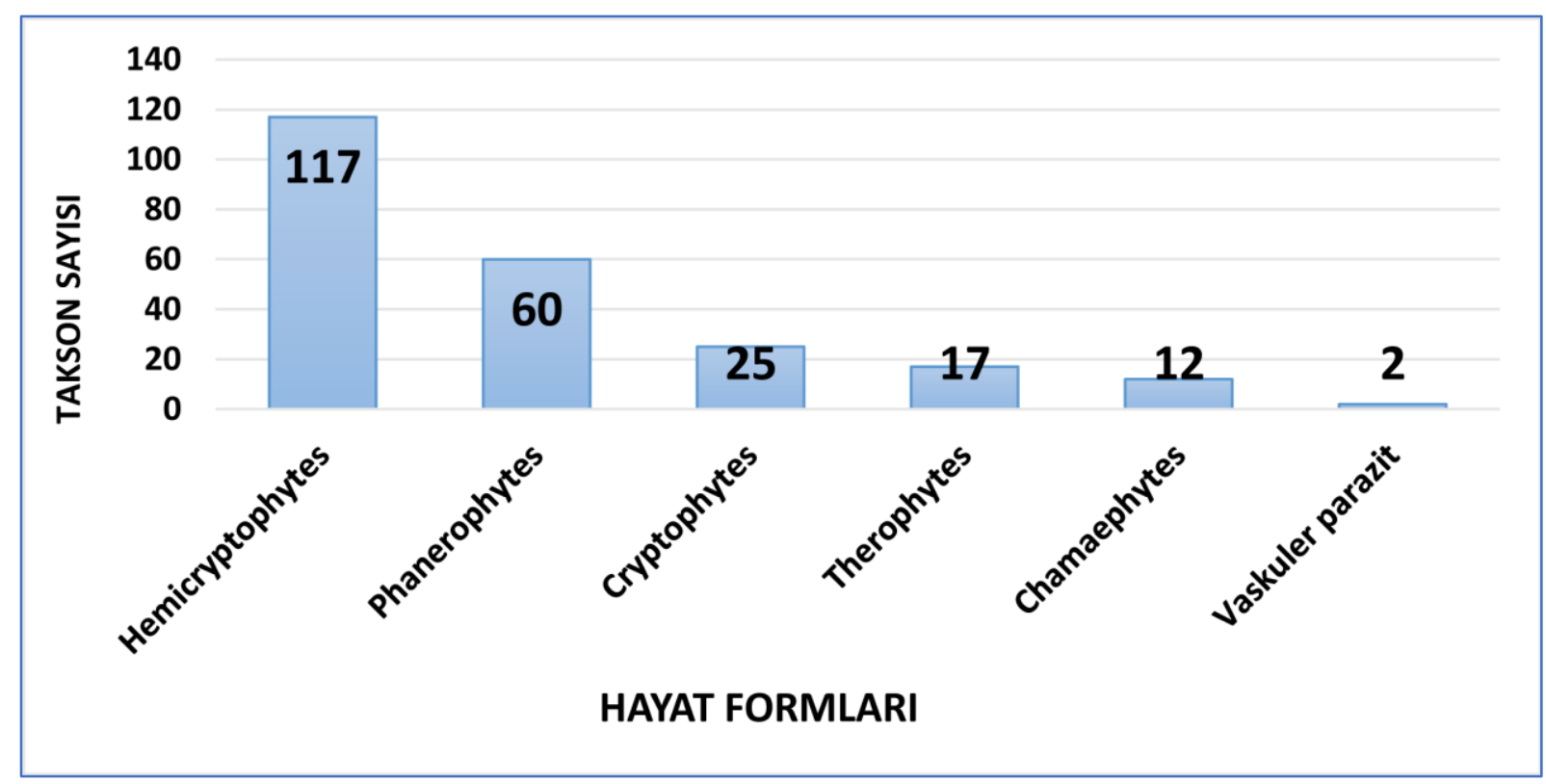

Şekil 3. Kızılcasu OPB'nde tespit edilen taksonların hayat formları dă̆ılımı

Tablo 1. Kızılcasu OPB'nde tespit edilen taksonlar

\begin{tabular}{|c|c|c|c|}
\hline & Takson & Koroloji & Hayat Formu \\
\hline & Equisetaceae & & \\
\hline \multirow[t]{2}{*}{1} & Equisetum arvense $\mathrm{L}$. & Çok Bölge & $\mathrm{Cr}$ \\
\hline & Dennstaedtiaceae & & \\
\hline \multirow[t]{2}{*}{2} & Pteridium aquilinum (L.) Kuhn & Çok Bölge & $\mathrm{Cr}$ \\
\hline & Dryopteridaceae & & \\
\hline \multirow[t]{2}{*}{3} & Dryopteris filix-mas (L.) Schott & Çok Bölge & $\mathrm{Cr}$ \\
\hline & Cupressaceae & & \\
\hline \multirow[t]{2}{*}{4} & Juniperus oxycedrus L. subsp. oxycedrus & Çok Bölge & $\mathrm{Ph}$ \\
\hline & Pinaceae & & \\
\hline 5 & Abies nordmanniana (Steven) Spach subsp. equi-trojani (Asc. \& Sint. ex Boiss.) Coode \& Cullen & Öksin & $\mathrm{Ph}$ \\
\hline 6 & Pinus nigra J.F.Arnold subsp. pallasiana (Lamb.) Holmboe & Çok Bölge & $\mathrm{Ph}$ \\
\hline \multirow[t]{2}{*}{7} & Pinus sylvestris L. var. hamata Steven & Avr-Sib & $\mathrm{Ph}$ \\
\hline & Adoxaceae & & \\
\hline 8 & Sambucus ebulus L. & Avr-Sib & $\mathrm{H}$ \\
\hline \multirow[t]{2}{*}{9} & Sambucus nigra L. & Avr-Sib & $\mathrm{Ph}$ \\
\hline & Amaryllidaceae & & \\
\hline \multirow[t]{2}{*}{10} & Galanthus plicatus M.Bieb. subsp. plicatus & Öksin & $\mathrm{Cr}$ \\
\hline & Anacardiaceae & & \\
\hline \multirow[t]{2}{*}{11} & Rhus coriaria $\mathrm{L}$. & Çok Bölge & $\mathrm{Ph}$ \\
\hline & Aquifoliaceae & & \\
\hline \multirow[t]{2}{*}{12} & Ilex colchica Pojark. & Öksin & $\mathrm{Ph}$ \\
\hline & Araliaceae & & \\
\hline \multirow[t]{2}{*}{13} & Hedera helix $\mathrm{L}$. & Çok Bölge & $\mathrm{Ph}$ \\
\hline & Asparagaceae & & \\
\hline
\end{tabular}


Tablo 1. (devam) Kuzllcasu OPB'nde tespit edilen taksonlar

\begin{tabular}{|c|c|c|c|}
\hline 14 & Muscari armeniacum Leichtlin ex Baker & Çok Bölge & $\mathrm{Cr}$ \\
\hline 15 & Polygonatum orientale Desf. & Öksin & $\mathrm{H}$ \\
\hline 16 & Ruscus hypoglossum $\mathrm{L}$. & Avr-Sib & $\mathrm{H}$ \\
\hline \multirow[t]{2}{*}{17} & Scilla bifolia $\mathrm{L}$. & Akd & $\mathrm{Cr}$ \\
\hline & Asteraceae & & \\
\hline 18 & Achillea biserrata M.Bieb. & Öksin & $\mathrm{H}$ \\
\hline 19 & Achillea millefolium L. subsp. millefolium & Avr-Sib & $\mathrm{H}$ \\
\hline 20 & Arctium minus (Hill) Bernh. & Avr-Sib & $\mathrm{H}$ \\
\hline 21 & Bellis perennis $\mathrm{L}$. & Avr-Sib & $\mathrm{H}$ \\
\hline 22 & Centaurea phrygia L. subsp. stenolepis (Kerner) Gugler & Avr-Sib & $\mathrm{H}$ \\
\hline 23 & Cichorium intybus $\mathrm{L}$. & Çok Bölge & $\mathrm{H}$ \\
\hline 24 & Cirsium arvense (L.) Scop. & Çok Bölge & $\mathrm{H}$ \\
\hline 25 & Cirsium hypoleucum DC. & Öksin & $\mathrm{H}$ \\
\hline 26 & Cirsium vulgare (Savi) Ten. & Çok Bölge & $\mathrm{H}$ \\
\hline 27 & Cota tinctoria (L.) J.Gay var. pallida (DC.) Özbek \& Vural & Çok Bölge & $\mathrm{H}$ \\
\hline 28 & Doronicum orientale Hoffm. & Çok Bölge & $\mathrm{Cr}$ \\
\hline 29 & Eupatorium cannabinum $\mathrm{L}$. & Avr-Sib & $\mathrm{H}$ \\
\hline 30 & Filago germanica (L.) L. & Çok Bölge & $\mathrm{Th}$ \\
\hline 31 & Helichrysum arenarium (L.) Moench subsp. aucheri (Boiss.) P.H.Davis \& Kupicha & İr-Tur & $\mathrm{Ch}$ \\
\hline 32 & Lapsana communis L. subsp. intermedia (M.Bieb.) Hayek & Çok Bölge & $\mathrm{H}$ \\
\hline 33 & Leontodon hispidus L. subsp. hastilis (L.) Corb. & Avr-Sib & $\mathrm{H}$ \\
\hline 34 & Petasites hybridus (L.) G.Gaertn., B.Mey. \& Scherb. & Avr-Sib & $\mathrm{H}$ \\
\hline 35 & Pilosella hoppeana (Schult.) F.W.Schultz \& Sch.Bip. subsp. hoppeana & Çok Bölge & $\mathrm{H}$ \\
\hline 36 & Pilosella hoppeana subsp. testimonialis (Nägeli ex Peter) P.D.Sell \& C.West & Çok Bölge & $\mathrm{H}$ \\
\hline 37 & Pilosella piloselloides (Vill.) Soják subsp. piloselloides & Çok Bölge & $\mathrm{H}$ \\
\hline 38 & Pulicaria dysenterica (L.) Bernh. subsp. dysenterica & Çok Bölge & $\mathrm{H}$ \\
\hline 39 & Tanacetum parthenium (L.) Sch.Bip. & Çok Bölge & $\mathrm{H}$ \\
\hline 40 & Tanacetum poteriifolium (Ledeb.) Grierson & Öksin & $\mathrm{H}$ \\
\hline 41 & Telekia speciosa (Schreb.) Baumg. & Avr-Sib & $\mathrm{H}$ \\
\hline 42 & Tragopogon porrifolius L. subsp. abbreviatus (Boiss.) Coşkunçelebi \& M.Gultepe & Çok Bölge & $\mathrm{H}$ \\
\hline \multirow[t]{2}{*}{43} & Tussilago farfara $\mathrm{L}$. & Avr-Sib & $\mathrm{Cr}$ \\
\hline & Apiaceae & & \\
\hline 44 & Daucus carota $\mathrm{L}$. & Çok Bölge & $\mathrm{H}$ \\
\hline 45 & Peucedanum aegopodioides (Boiss.) Vandas & Avr-Sib & $\mathrm{H}$ \\
\hline \multirow[t]{2}{*}{46} & Sanicula europaea $\mathrm{L}$. & Avr-Sib & $\mathrm{H}$ \\
\hline & Betulaceae & & \\
\hline 47 & Alnus glutinosa (L.) Gaertn. subsp. glutinosa & Avr-Sib & $\mathrm{Ph}$ \\
\hline 48 & Carpinus betulus $\mathrm{L}$. & Avr-Sib & $\mathrm{Ph}$ \\
\hline 49 & Corylus avellana $\mathrm{L}$. var. avellana & Avr-Sib & $\mathrm{Ph}$ \\
\hline 50 & Corylus colurna $\mathrm{L}$. & Avr-Sib & $\mathrm{Ph}$ \\
\hline \multirow[t]{2}{*}{51} & Ostrya carpinifolia Scop. & Akd & $\mathrm{Ph}$ \\
\hline & Boraginaceae & & \\
\hline
\end{tabular}


Tablo 1. (devam) Kuzllcasu OPB'nde tespit edilen taksonlar

\begin{tabular}{|c|c|c|c|}
\hline 52 & Aegonychon purpurocaeruleum (L.) Holub & Avr-Sib & $\mathrm{H}$ \\
\hline 53 & Cynoglossum creticum Mill. & Çok Bölge & $\mathrm{H}$ \\
\hline 54 & Echium vulgare $\mathrm{L}$. subsp. vulgare & Avr-Sib & $\mathrm{H}$ \\
\hline 55 & Myosotis lithospermifolia Hornem. & Çok Bölge & $\mathrm{H}$ \\
\hline \multirow[t]{2}{*}{56} & Trachystemon orientalis (L.) G.Don & Öksin & $\mathrm{Cr}$ \\
\hline & Brassicaceae & & \\
\hline 57 & Capsella bursa-pastoris (L.) Medik. & Çok Bölge & $\mathrm{Th}$ \\
\hline 58 & Cardamine impatiens L. subsp. pectinata (Pall. ex DC.) Stoj. \& Stef. & Avr-Sib & Th \\
\hline \multirow[t]{2}{*}{59} & Cardamine quinquefolia (M.Bieb.) Schmalh. & Avr-Sib & $\mathrm{H}$ \\
\hline & Buxaceae & & \\
\hline \multirow[t]{2}{*}{60} & Buxus sempervirens $\mathrm{L}$. subsp. sempervirens & Avr-Sib & $\mathrm{Ph}$ \\
\hline & Campanulaceae & & \\
\hline 61 & Campanula glomerata L. subsp. hispida (Witasek) Hayek & Avr-Sib & $\mathrm{H}$ \\
\hline 62 & Campanula latifolia $\mathrm{L}$. subsp. latifolia & Avr-Sib & $\mathrm{H}$ \\
\hline 63 & Campanula olympica Boiss. & Öksin & $\mathrm{H}$ \\
\hline 64 & Campanula rapunculoides $\mathrm{L}$. & Avr-Sib & $\mathrm{H}$ \\
\hline \multirow[t]{2}{*}{65} & Campanula rapunculus L. subsp. lambertiana (A.DC.) Rech.f. & Çok Bölge & $\mathrm{H}$ \\
\hline & Caryophyllaceae & & \\
\hline 66 & Dianthus calocephalus Boiss. & Çok Bölge & $\mathrm{H}$ \\
\hline 67 & Silene compacta Fisch. ex Hornem. & Çok Bölge & $\mathrm{H}$ \\
\hline 68 & Silene vulgaris (Moench) Garcke var. vulgaris & Çok Bölge & $\mathrm{H}$ \\
\hline \multirow[t]{2}{*}{69} & Stellaria holostea $\mathrm{L}$. & Avr-Sib & $\mathrm{Ch}$ \\
\hline & Celastraceae & & \\
\hline \multirow[t]{2}{*}{70} & Euonymus latifolius Mill. subsp. latifolius & Avr-Sib & $\mathrm{Ph}$ \\
\hline & Cistaceae & & \\
\hline \multirow[t]{2}{*}{71} & Helianthemum nuтmularium (L.) Mill. subsp. nummularium & Çok Bölge & $\mathrm{Ch}$ \\
\hline & Convolvulaceae & & \\
\hline 72 & Convolvulus arvensis $\mathrm{L}$. & Çok Bölge & $\mathrm{H}$ \\
\hline \multirow[t]{2}{*}{73} & Convolvulus scammonia $\mathrm{L}$. & D. Akd & $\mathrm{H}$ \\
\hline & Cornaceae & & \\
\hline 74 & Cornus mas $\mathrm{L}$. & Avr-Sib & $\mathrm{Ph}$ \\
\hline \multirow[t]{2}{*}{75} & Cornus sanguinea L. subsp. australis (C.A.Mey.) Jáv. & Avr-Sib & $\mathrm{Ph}$ \\
\hline & Crassulaceae & & \\
\hline \multirow[t]{2}{*}{76} & Sedum pallidum M.Bieb. & Öksin & $\mathrm{H}$ \\
\hline & Caprifoliaceae & & \\
\hline 77 & Dipsacus laciniatus $\mathrm{L}$. & Çok Bölge & $\mathrm{H}$ \\
\hline 78 & Scabiosa columbaria L. subsp. columbaria var. columbaria & Çok Bölge & $\mathrm{H}$ \\
\hline 79 & Scabiosa columbaria L. subsp. ochroleuca (L.) Čélak. var. ochroleuca & Çok Bölge & $\mathrm{H}$ \\
\hline \multirow[t]{2}{*}{80} & Valeriana alliariifolia Adams & Çok Bölge & $\mathrm{H}$ \\
\hline & Dioscoreaceae & & \\
\hline 81 & Dioscorea communis (L.) Caddick \& Wilkin & Çok Bölge & $\mathrm{Cr}$ \\
\hline
\end{tabular}


Tablo 1. (devam) Kuzllcasu OPB'nde tespit edilen taksonlar

\begin{tabular}{|c|c|c|c|}
\hline 82 & Erica arborea $\mathrm{L}$. & Çok Bölge & $\mathrm{Ph}$ \\
\hline 83 & Monotropa hypopithys L. & Çok Bölge & Vas. Parazit \\
\hline 84 & Pyrola media $\mathrm{Sw}$. & Avr-Sib & $\mathrm{H}$ \\
\hline 85 & Rhododendron luteum Sweet & Öksin & $\mathrm{Ph}$ \\
\hline 86 & Rhododendron ponticum L. & Öksin & $\mathrm{Ph}$ \\
\hline \multirow[t]{2}{*}{87} & Vaccinium arctostaphylos $\mathrm{L}$. & Öksin & $\mathrm{Ph}$ \\
\hline & Euphorbiaceae & & \\
\hline 88 & Euphorbia amygdaloides L. subsp. amygdaloides & Avr-Sib & $\mathrm{H}$ \\
\hline \multirow[t]{2}{*}{89} & Euphorbia stricta L. & Avr-Sib & Th \\
\hline & Fabaceae & & \\
\hline 90 & Dorycnium pentaphyllum Scop. subsp. anatolicum (Boiss.) Gams & Çok Bölge & $\mathrm{Ch}$ \\
\hline 91 & Astragalus glycyphylloides DC. & Avr-Sib & $\mathrm{H}$ \\
\hline 92 & Bituminaria bituminosa (L.) C.H.Stirt. & Akd & $\mathrm{H}$ \\
\hline 93 & Genista tinctoria $\mathrm{L}$. & Avr-Sib & $\mathrm{Ph}$ \\
\hline 94 & Lathyrus laxiflorus (Desf.) O.Kuntze subsp. laxiflorus & Çok Bölge & $\mathrm{H}$ \\
\hline 95 & Lathyrus pratensis L. & Avr-Sib & $\mathrm{H}$ \\
\hline 96 & Lotus corniculatus L. var. corniculatus & Çok Bölge & $\mathrm{H}$ \\
\hline 97 & Melilotus officinalis (L.) Desr. & Çok Bölge & Th \\
\hline 98 & Securigera varia (L.) Lassen & Çok Bölge & $\mathrm{H}$ \\
\hline 99 & Sophora alopecuroides L. var. alopecuroides & Çok Bölge & $\mathrm{Cr}$ \\
\hline 100 & Trifolium arvense L. var. arvense & Çok Bölge & $\mathrm{H}$ \\
\hline 101 & Trifolium pratense L. var. pratense & Çok Bölge & $\mathrm{H}$ \\
\hline 102 & Trifolium repens $\mathrm{L}$. var. repens & Çok Bölge & $\mathrm{Th}$ \\
\hline 103 & Vicia cracca L. subsp. stenophylla Vel. & Çok Bölge & $\mathrm{H}$ \\
\hline 104 & Vicia freyniana Bornm. & Öksin & $\mathrm{H}$ \\
\hline \multirow[t]{2}{*}{105} & Vicia villosa Roth subsp. villosa & Çok Bölge & $\mathrm{Th}$ \\
\hline & Fagaceae & & \\
\hline 106 & Castanea sativa Mill. & Avr-Sib & $\mathrm{Ph}$ \\
\hline 107 & Fagus orientalis Lipsky & Avr-Sib & $\mathrm{Ph}$ \\
\hline 108 & Quercus petraea (Matt.) Liebl. subsp. iberica (Steven ex M.Bieb.) Krassiln. & Çok Bölge & $\mathrm{Ph}$ \\
\hline \multirow[t]{2}{*}{109} & Quercus pubescens Willd. & Çok Bölge & $\mathrm{Ph}$ \\
\hline & Gentianaceae & & \\
\hline 110 & Blackstonia perfoliata (L.) Huds. subsp. perfoliata & Çok Bölge & $\mathrm{Th}$ \\
\hline 111 & Centaurium erythraea Rafn. subsp. erythraea & Avr-Sib & $\mathrm{H}$ \\
\hline 112 & Gentiana asclepiadea L. & Avr-Sib & $\mathrm{H}$ \\
\hline \multirow[t]{2}{*}{113} & Gentiana cruciata L. & Avr-Sib & $\mathrm{H}$ \\
\hline & Geraniaceae & & \\
\hline 114 & Geranium macrostylum Boiss. & D. Akd & $\mathrm{H}$ \\
\hline \multirow[t]{2}{*}{115} & Geranium robertianum $\mathrm{L}$. & Çok Bölge & $\mathrm{Th}$ \\
\hline & Hypericaceae & & \\
\hline 116 & Hypericum androsaemum $\mathrm{L}$. & Avr-Sib & $\mathrm{H}$ \\
\hline 117 & Hypericum bithynicum Boiss. & Öksin & $\mathrm{H}$ \\
\hline
\end{tabular}


Tablo 1. (devam) Kuzllcasu OPB'nde tespit edilen taksonlar

\begin{tabular}{|c|c|c|c|}
\hline 118 & Hypericum perforatum $\mathrm{L}$. & Çok Bölge & $\mathrm{H}$ \\
\hline & Juglandaceae & & \\
\hline \multirow[t]{2}{*}{119} & Juglans regia $\mathrm{L}$. & Çok Bölge & $\mathrm{Ph}$ \\
\hline & Lamiaceae & & \\
\hline 120 & Ajuga orientalis L. & Çok Bölge & $\mathrm{H}$ \\
\hline 121 & Ajuga reptans $\mathrm{L}$. & Avr-Sib & $\mathrm{H}$ \\
\hline 122 & Clinopodium grandiflorum (L.) Kuntze & Avr-Sib & $\mathrm{H}$ \\
\hline 123 & Clinopodium vulgare L. subsp. arundanum (Boiss.) Nyman & Çok Bölge & $\mathrm{H}$ \\
\hline 124 & Lamium maculatum L. & Avr-Sib & $\mathrm{H}$ \\
\hline 125 & Leonurus cardiaca $\mathrm{L}$. & Avr-Sib & $\mathrm{H}$ \\
\hline 126 & Mentha pulegium $\mathrm{L}$. & Çok Bölge & $\mathrm{H}$ \\
\hline 127 & Origanum vulgare L. subsp. vulgare & Avr-Sib & $\mathrm{H}$ \\
\hline 128 & Prunella vulgaris L. & Avr-Sib & $\mathrm{H}$ \\
\hline 129 & Salvia forskahlei $\mathrm{L}$. & Öksin & $\mathrm{H}$ \\
\hline 130 & Salvia glutinosa $\mathrm{L}$. & Hir-Öksin & $\mathrm{H}$ \\
\hline 131 & Salvia verticillata L. subsp. amasiaca (Freyn \& Bornm.) Bornm. & Avr-Sib & $\mathrm{H}$ \\
\hline 132 & Salvia viridis $\mathrm{L}$. & Akd & $\mathrm{H}$ \\
\hline 133 & Satureja wiedemanniana (Avé-Lall.) Velen. & Çok Bölge & $\mathrm{Ch}$ \\
\hline 134 & Scutellaria altissima $\mathrm{L}$. & Avr-Sib & $\mathrm{H}$ \\
\hline 135 & Stachys iberica M.Bieb. subsp. iberica var. densipilosa R.Bhattacharjee & İr-Tur & $\mathrm{Ch}$ \\
\hline 136 & Stachys iberica M.Bieb. subsp. iberica var. iberica & İr-Tur & $\mathrm{Ch}$ \\
\hline 137 & Stachys setifera C.A.Mey. subsp. lycia (Gand.) R.Bhattacharjee & İr-Tur & $\mathrm{H}$ \\
\hline \multirow[t]{2}{*}{138} & Teucrium chamaedrys L. subsp. chamaedrys & Avr-Sib & $\mathrm{H}$ \\
\hline & Liliaceae & & \\
\hline \multirow[t]{2}{*}{139} & Lilium martagon $\mathrm{L}$. & Avr-Sib & $\mathrm{Cr}$ \\
\hline & Lythraceae & & \\
\hline \multirow[t]{2}{*}{140} & Lythrum salicaria $\mathrm{L}$. & Avr-Sib & $\mathrm{H}$ \\
\hline & Malvaceae & & \\
\hline 141 & Alcea biennis Winterl & İr-Tur & $\mathrm{H}$ \\
\hline 142 & Malva alcea $\mathrm{L}$. & Çok Bölge & $\mathrm{H}$ \\
\hline \multirow[t]{2}{*}{143} & Tilia rubra subsp. caucasica (Rupr.) V.Engl. & Öksin & $\mathrm{Ph}$ \\
\hline & Oleaceae & & \\
\hline \multirow[t]{2}{*}{144} & Fraxinus excelsior L. subsp. excelsior & Avr-Sib & $\mathrm{Ph}$ \\
\hline & Onagraceae & & \\
\hline 145 & Circaea lutetiana $\mathrm{L}$. & Çok Bölge & $\mathrm{H}$ \\
\hline 146 & Epilobium angustifolium $\mathrm{L}$. & Çok Bölge & $\mathrm{H}$ \\
\hline 147 & Epilobium hirsutum L. & Çok Bölge & $\mathrm{H}$ \\
\hline \multirow[t]{2}{*}{148} & Epilobium montanum L. & Avr-Sib & $\mathrm{H}$ \\
\hline & Orchidaceae & & \\
\hline 149 & Anacamptis pyramidalis (L.)L.C.M.Richard & Çok Bölge & $\mathrm{Cr}$ \\
\hline 150 & Cephalanthera rubra (L.) Rich. & Çok Bölge & $\mathrm{Cr}$ \\
\hline 151 & Dactylorhiza romana (Seb.) Soó subsp. romana & Akd & $\mathrm{Cr}$ \\
\hline
\end{tabular}


Tablo 1. (devam) Kuzllcasu OPB'nde tespit edilen taksonlar

\begin{tabular}{|c|c|c|c|}
\hline 152 & Dactylorhiza urvilleana (Steudel) Baumann \& Künkele subsp. urvilleana & Öksin & $\mathrm{Cr}$ \\
\hline 153 & Ophrys oestrifera M.Bieb. subsp. oestrifera & Çok Bölge & $\mathrm{Cr}$ \\
\hline \multirow[t]{2}{*}{154} & Orchis purpurea Huds. & Avr-Sib & $\mathrm{Cr}$ \\
\hline & Orobanchaceae & & \\
\hline 155 & Rhinanthus angustifolius C.C.Gmel. subsp. grandiflorus (Wallr.) D.A. Webb & Çok Bölge & $\mathrm{Th}$ \\
\hline 156 & Euphrasia pectinata Ten. & Avr-Sib & Th \\
\hline 157 & Lathraea squamaria $\mathrm{L}$. & Avr-Sib & Vas. Parazit \\
\hline 158 & Melampyrum arvense L. var. arvense & Avr-Sib & $\mathrm{Th}$ \\
\hline \multirow[t]{2}{*}{159} & Rhynchocorys elephas (L.) Griseb. subsp. elephas & Avr-Sib & $\mathrm{H}$ \\
\hline & Papaveraceae & & \\
\hline \multirow[t]{2}{*}{160} & Corydalis cava (L.) Schweigg. \& Körte subsp. cava & Çok Bölge & $\mathrm{Cr}$ \\
\hline & Plantaginaceae & & \\
\hline 161 & Digitalis ferruginea L. subsp. ferruginea & Avr-Sib & $\mathrm{H}$ \\
\hline 162 & Digitalis lamarckii Ivanina & İr-Tur & $\mathrm{H}$ \\
\hline 163 & Plantago major L. subsp. major & Çok Bölge & $\mathrm{H}$ \\
\hline 164 & Veronica chamaedrys L. & Avr-Sib & $\mathrm{Cr}$ \\
\hline 165 & Veronica magna M.A. Fisch. & Öksin & $\mathrm{H}$ \\
\hline \multirow[t]{2}{*}{166} & Veronica pectinata L. var. pectinata & Çok Bölge & $\mathrm{H}$ \\
\hline & Platanaceae & & \\
\hline \multirow[t]{2}{*}{167} & Platanus orientalis L. & Çok Bölge & $\mathrm{Ph}$ \\
\hline & Poaceae & & \\
\hline 168 & Briza media L. & Çok Bölge & $\mathrm{H}$ \\
\hline \multirow[t]{2}{*}{169} & Hordeum murinum L. subsp. murinum & Çok Bölge & $\mathrm{H}$ \\
\hline & Polygalaceae & & \\
\hline \multirow[t]{2}{*}{170} & Polygala major Jacq. & Avr-Sib & $\mathrm{H}$ \\
\hline & Polygonaceae & & \\
\hline 171 & Rumex acetosella $\mathrm{L}$. & Kozmopolit & $\mathrm{H}$ \\
\hline 172 & Rumex crispus $\mathrm{L}$. & Çok Bölge & $\mathrm{H}$ \\
\hline \multirow[t]{2}{*}{173} & Rumex obtusifolius L. subsp. subalpinus (Schur) Celak. & Çok Bölge & $\mathrm{H}$ \\
\hline & Primulaceae & & \\
\hline 174 & Anagallis arvensis L. var. arvensis & Çok Bölge & Th \\
\hline 175 & Lysimachia verticillaris Spreng. & Öksin & $\mathrm{Cr}$ \\
\hline 176 & Primula acaulis (L.) L. subsp. acaulis & Öksin & $\mathrm{H}$ \\
\hline \multirow[t]{2}{*}{177} & Primula acaulis (L.) L. subsp. rubra (Sm.) Greuter \& Burdet & Öksin & $\mathrm{H}$ \\
\hline & Ranunculaceae & & \\
\hline 178 & Clematis vitalba $\mathrm{L}$. & Çok Bölge & $\mathrm{Ph}$ \\
\hline 179 & Consolida orientalis (J.Gay) Schrödinger & Çok Bölge & $\mathrm{Th}$ \\
\hline 180 & Helleborus orientalis Lam. & Öksin & $\mathrm{H}$ \\
\hline 181 & Ranunculus arvensis L. & Çok Bölge & $\mathrm{Th}$ \\
\hline 182 & Ranunculus constantinopolitanus (DC.) d'Urv. & Kozmopolit & $\mathrm{H}$ \\
\hline 183 & Ranunculus illyricus L. & Çok Bölge & $\mathrm{Cr}$ \\
\hline 184 & Ranunculus repens $\mathrm{L}$. & Çok Bölge & $\mathrm{H}$ \\
\hline
\end{tabular}


Tablo 1. (devam) Kuzllcasu OPB'nde tespit edilen taksonlar

\begin{tabular}{|c|c|c|c|}
\hline & Rosaceae & & \\
\hline 185 & Agrimonia eupatoria L. subsp. eupatoria & Çok Bölge & $\mathrm{H}$ \\
\hline 186 & Alchemilla caucasica Buser & Eux. (mt) & $\mathrm{Cr}$ \\
\hline 187 & Crataegus microphylla K.Koch subsp. microphylla & Hir-Öksin & $\mathrm{Ph}$ \\
\hline 188 & Crataegus orientalis Pall. ex M.Bieb. subsp. orientalis & Çok Bölge & $\mathrm{Ph}$ \\
\hline 189 & Crataegus rhipidophylla Gand. var. rhipidophylla & Çok Bölge & $\mathrm{Ph}$ \\
\hline 190 & Fragaria vesca $\mathrm{L}$. & Çok Bölge & $\mathrm{H}$ \\
\hline 191 & Geum urbanum $\mathrm{L}$. & Avr-Sib & $\mathrm{Ch}$ \\
\hline 192 & Laurocerasus officinalis M.Roem. & Çok Bölge & $\mathrm{Ph}$ \\
\hline 193 & Malus sylvestris (L.) Mill. subsp. orientalis var. orientalis (Uglitzk.) Browicz & Çok Bölge & $\mathrm{Ph}$ \\
\hline 194 & Mespilus germanica $\mathrm{L}$. & Çok Bölge & $\mathrm{Ph}$ \\
\hline 195 & Potentilla reptans $\mathrm{L}$. & Çok Bölge & $\mathrm{H}$ \\
\hline 196 & Prunus divaricata Ledeb. var. divaricata & Çok Bölge & $\mathrm{Ph}$ \\
\hline 197 & Prunus spinosa $\mathrm{L}$. & Avr-Sib & $\mathrm{Ph}$ \\
\hline 198 & Pyracantha coccinea M.Roem. & Çok Bölge & $\mathrm{Ph}$ \\
\hline 199 & Pyrus communis L. subsp. communis & Çok Bölge & $\mathrm{Ph}$ \\
\hline 200 & Pyrus elaeagnifolia Pall. subsp. elaeagnifolia & Çok Bölge & $\mathrm{Ph}$ \\
\hline 201 & Rosa boissieri Crép. & Çok Bölge & $\mathrm{Ph}$ \\
\hline 202 & Rosa canina $\mathrm{L}$. & Çok Bölge & $\mathrm{Ph}$ \\
\hline 203 & Rubus canescens DC. var. canescens & Avr-Sib & $\mathrm{Ch}$ \\
\hline 204 & Rubus hirtus Waldst. \& Kit. & Avr-Sib & $\mathrm{Ch}$ \\
\hline 205 & Rubus sanctus Schreb. & Çok Bölge & $\mathrm{Ch}$ \\
\hline 206 & Sanguisorba minor L. subsp. balearica (Bourg. ex Nyman) Muñoz Garm. \& C.Navarro & Çok Bölge & $\mathrm{H}$ \\
\hline \multirow[t]{2}{*}{207} & Sorbus torminalis (L.) Crantz var. torminalis & Avr-Sib & $\mathrm{Ph}$ \\
\hline & Rubiaceae & & \\
\hline 208 & Galium odoratum (L.) Scop. & Avr-Sib & $\mathrm{Cr}$ \\
\hline 209 & Galium palustre $\mathrm{L}$. & Avr-Sib & $\mathrm{Ch}$ \\
\hline 210 & Galium rotundifolium $\mathrm{L}$. & Avr-Sib & $\mathrm{Cr}$ \\
\hline \multirow[t]{2}{*}{211} & Galium verum L. subsp. verum & Avr-Sib & $\mathrm{H}$ \\
\hline & Salicaceae & & \\
\hline 212 & Populus nigra L. subsp. nigra & Çok Bölge & $\mathrm{Ph}$ \\
\hline 213 & Populus tremula $\mathrm{L}$. & Çok Bölge & $\mathrm{Ph}$ \\
\hline 214 & Salix alba L. subsp. alba & Avr-Sib & $\mathrm{Ph}$ \\
\hline 215 & Salix amplexicaulis Bory \& Chaub. & Akd & $\mathrm{Ph}$ \\
\hline 216 & Salix caprea $\mathrm{L}$. & Avr-Sib & $\mathrm{Ph}$ \\
\hline \multirow[t]{2}{*}{217} & Salix elaeagnos Scop. & Avr-Sib & $\mathrm{Ph}$ \\
\hline & Sapindaceae & & \\
\hline 218 & Acer platanoides $\mathrm{L}$. & Avr-Sib & $\mathrm{Ph}$ \\
\hline 219 & Acer campestre L. subsp. campestre & Avr-Sib & $\mathrm{Ph}$ \\
\hline 220 & Acer heldreichii Orph. ex Boiss. subsp. trautvetteri (Medw.) A.E.Murray & Öksin & $\mathrm{Ph}$ \\
\hline \multirow[t]{2}{*}{221} & Acer hyrcanum Fisch. \& C.A.Mey. subsp. hyrcanum & Avr-Sib & $\mathrm{Ph}$ \\
\hline & Saxifragaceae & & \\
\hline
\end{tabular}


Tablo 1. (devam) Kuzllcasu OPB'nde tespit edilen taksonlar

\begin{tabular}{|c|c|c|c|}
\hline 222 & Saxifraga cymbalaria $\mathrm{L}$. & Çok Bölge & Th \\
\hline & Scrophulariaceae & & \\
\hline \multirow[t]{2}{*}{223} & Verbascum freynii (Sint.) Murb. & Öksin & $\mathrm{H}$ \\
\hline & Smilacaceae & & \\
\hline \multirow[t]{2}{*}{224} & Smilax excelsa $\mathrm{L}$. & Çok Bölge & $\mathrm{Ph}$ \\
\hline & Solanaecae & & \\
\hline \multirow[t]{2}{*}{225} & Atropa belladonna $\mathrm{L}$. & Avr-Sib & $\mathrm{H}$ \\
\hline & Staphyleaceae & & \\
\hline \multirow[t]{2}{*}{226} & Staphylea pinnata $\mathrm{L}$. & Çok Bölge & $\mathrm{Ph}$ \\
\hline & Taxaceae & & \\
\hline \multirow[t]{2}{*}{227} & Taxus baccata $\mathrm{L}$. & Çok Bölge & $\mathrm{Ph}$ \\
\hline & Thymelaeaceae & & \\
\hline \multirow[t]{2}{*}{228} & Daphne pontica L. subsp. pontica & Öksin & $\mathrm{Ph}$ \\
\hline & Ulmaceae & & \\
\hline \multirow[t]{2}{*}{229} & Ulmus glabra Huds. & Avr-Sib & $\mathrm{Ph}$ \\
\hline & Urticaceae & & \\
\hline \multirow[t]{2}{*}{230} & Urtica dioica L. subsp. dioica & Avr-Sib & $\mathrm{H}$ \\
\hline & Violaceae & & \\
\hline 231 & Viola sieheana W.Becker & Çok Bölge & $\mathrm{H}$ \\
\hline 232 & Viola kitaibeliana Roem. \& Schult. & Çok Bölge & Th \\
\hline 233 & Viola suavis M.Bieb. & Çok Bölge & $\mathrm{H}$ \\
\hline
\end{tabular}

Diğer kategorilere ait bitkiler incelendiğinde ise; Helichrysum arenarium subsp. aucheri (Boiss.) P.H.Davis \& Kupicha (endemik-LC) Gökgöl deresi kenarında dar bir yayılışı vardır, Satureja wiedemanniana (Avé-Lall.) Velen. (endemik-LC) ve Stachys iberica subsp. iberica var. densipilosa R.Bhattacharjee (endemik-LC) taksonları Harmancık mahallesinde bulunan meşelik alan kenarında güney bakıda yayılış yapmaktadır, Stachys setifera subsp. lycia (Gand.) R.Bhattacharjee (endemik-LC) ve Vicia freyniana Bornm. (endemik-LC) Doğu Kayını ve Kazdağı Göknarı orman kenarında gölgeli ve nemli alanlarda yayılış yapmaktadırlar. Abies nordmanniana subsp. equi-trojani (Asc. \& Sint. ex Boiss.) Coode \& Cullen (Syn.: Abies nordmanniana subsp. bornmuelleriana (Mattf.) Coode \& Cullen) (endemik-LC) taksonu ise planlama biriminde hem saf meşcereler hem de doğu kayını ve sarıçam türleriyle birlikte karışık orman kuruluşları yapmakta olup, büyük oranda kuzey bakı grubunu tercih etmektedir. Verbascum freynii (Sint.) Murb. (endemik-VU) ve Digitalis lamarckii Ivanina (endemikLC), Turnacık mevkiinde Kazdağı Göknarı-Karaçam ormanı açıklığında güney bakıda yayılış yapmaktadırlar. Bir nadir takson olan Lilium martagon L. ise (nadir-VU) planlama biriminde iki farklı yayılış alanına sahiptir. Birincisi yangın gözetleme kulesinin yanında bulunan Kazdağı göknarı meşceresi altında olup, ikinci yayılışı ise eski orman işletme binasının bulunduğu Kazdağ göknarı-Adi Şimşir meşceresi altında yayılış yapmaktadır. Diğer bir nadir takson olan Leonurus cardiaca L. (nadirVU) ise Geyikgölü mevkiinde Kazdağı Göknarı-Doğu Kayını orman kenarında 1150 m'de yol şevinde dört adet bireyle yayılışını gerçekleştirmektedir. Leonurus cardiaca'nın planlama birimi içerisindeki bu yayılışı Kastamonu ili için yeni bir kayıttır. Diğer bir uluslararası koruma statüleri ise CITES ve Bern sözleşmeleri kapsamındaki taksonlardır. CITES kapsamında yer alan taksonlar Anacamptis pyramidalis (L.) Rich., Cephalanthera rubra (L.) Rich., Galanthus plicatus M. Bieb. subsp. plicatus, Orchis purpurea Huds. subsp. purpurea, Dactylorhiza romana (Seb.) Soó subsp. romana'dır. Çalışma alanında Bern sözleşmesi kapsamında ise Vaccinium arctostaphylos L. türü yer almaktadır. 


\section{TARTISMA VE SONUC}

Türkiye'de, Avrupa-Sibirya floristik bölgesi Öksin provens ile temsil edilmektedir [28]. Türkiye'de, Avrupa-Sibirya floristik bölgesi farklı araştırmacılar [13,29] tarafından farklı şekilde yorumlanmıştır. Zohary [29], Öksin provensi deniz seviyesinden İç Anadolu'ya doğru Asıl Öksin (Eu-Euxine), Alt Öksin (Sub-Euxine) ve Kurak Öksin (Xero-Euxine) olmak üzere üç bölüme ayırmıştır. Quézel vd. [13] ise yükselti basamakları baz alarak kıyısal Akdeniz kuşağı, Karadeniz içi Akdeniz kuşağı, Karadeniz öncesi üst Akdeniz kuşağı, Öksin öncesi dağ katı, Karadeniz az dağlı kuşağı ve Karadeniz dağ kuşağı olarak ayırmıştır. Çalışma alanı, Zohary [29]'ye göre Asıl Öksin , Quézel vd. [13]'e göre ise Karadeniz az dağlık katı içerisinde yer almakla birlikte, Karadeniz öncesi üst Akdeniz vejetasyon ve Karadeniz dağ katlarından da etkilenmektedir. Bu durum iklim konusunda da kendisini göstermiş olup, çalışma alanında üç farklı iklim tipinin hissedilmesine olanak sağlayarak farklı orman topluluklarının oluşmasına katkı sağlamıştır. Ormanlar, Öksin provensin klimatik vejetasyon tipidirler. Kuzey Anadolu'da alçak yükseltilerde nemli-1lıman geniş yapraklı ormanlar, yüksek kesimlerde ise nemli-yarı nemli ve kışı tolere eden iğne yapraklı orman toplulukları yayılış yapmaktadır [6, 7]. Çalışma kapsamında, Kızılcasu OPB içerisinde yayılış yapan Pinus nigra subsp. pallasiana, Pinus sylvestris var. hamata, Fagus orientalis, Abies nordmanniana subsp. equi-trojani ve Quercus petraea subsp. iberica taksonlarına ait mezofil ve termofil karakterli orman toplulukları doğal olarak yayılış yapmaktadırlar. Floristik çalışmalar koruma biyolojisi, orman yönetimi ya da ekolojik çalışmalar gibi uygulamalı bilim alanları için temel çalışmaların başında gelmektedir. Her ekosistemin kendisine ait özel ekolojik ve mikro klimatik karakterleri bulunmaktadır [27]. Bu habitatlarda yayılış yapan bitki taksonları, bu yaşam ortamlarına uyum sağlayarak ilgili habitatların indikatörleri olarak karşımıza çıkmaktadırlar. Bitki taksonlarının hangi floristik coğrafyaya ya da hangi hayat formuna sahip oluşu, bu indikatörlügün bir sonucudur [30].

Çalışma alanındaki bitki taksonlarının koroloji yönünden incelendiğinde, bitki taksonların büyük bir bölümünün $(\% 48,06)$ Avrupa-Sibirya floristik bölgesine ait olduğu görülmektedir. Bu taksonların çalışma alanındaki yoğun varlığı, incelenen alanın Öksin provens dolayısı ile Avrupa-Sibirya floristik bölgesi ile olan fitocoğrafik bağlantısının kanıtıdır [15, 31-32]. Çalışma kapsamında elde edilen bu sonuç, Kastamonu ilinde yapılan diğer çalışmalarda [15, 17-19] da elde edilmiştir. Diğer yandan çalışma alanında ikinci sırada \%3,5'luk oranı ile Akdeniz, üçüncü sırada ise \%2,6'lık oranı ile de İran-Turan floristik coğrafyalarına ait taksonlar yayılış yapmaktadır. Bu durum Kızılcasu OPB'nde hissedilen iklimden kaynaklanmaktadır. Nitekim, çalışma alanının kuzeybatısında Cide ve Kurucaşile bulunmaktadır. Bu bölgelerde bulunan Akdenizli ekosistemler [10] Kızılcasu'da yayılış yapan Akdeniz fitocoğrafik bölgesine ait taksonların varlığını açıklamaktadır. Araştırma alanındaki İran-Turan floristik bölgesine ait taksonlar ise yükselti ile birlikte hissedilen yar1-karasal iklimin etkisidir [33]. Bu sonuçlara çalışma alanı gibi Akdenizli ekosistemlerin varlığı bulunan Ketenoğlu ve Güney [18]'de de ulaşılmıştır. Fakat, Akdenizli ekosistemlerin etkisinin azaldığı bölgelerde $[15,17,19]$ ise ikinci sırada İran-Turan floristik coğrafyasının baskınlığı hissedilmektedir.

Daha önce de belirtildiği gibi Kızılcasu OPB'nde, Akdeniz, okyanusal ve yarı-karasal iklim tiplerinin etkileri bulunmaktadır. Bu durum floristik bölge yanında, alanda yayılış yapan bitki taksonlarının hayat formlarına da etki etmekte ve hayat formları spektrumlarının farklılaşmasına olanak sağlamaktadır. Bitki taksonlarının sahip olduğu yaşam formları yaşadıkları habitatlardaki ekolojik ve klimaya uyumlarını göstermektedir [27]. Bitki hayat formları herhangi bir alandaki genel iklimin bir yansımasıdır. Bu özellik yaşam formlarının mikro ve makro iklim indikatörü olmalarını sağlamaktadır $[30,34]$. Planlama birimi içerisinde Hemicryptophyte ve Phanerophyte karaktere sahip taksonların dominantlığ 1 bulunmaktadır. Hemicryptophyteler soğuk ve 1lıman [35], Phanerophyteler ise Akdenizli ekosistemlerin göstergeleridirler [30, 36]. Bu taksonların Kızılcasu OPB içerisinde yüksek miktarda bulunması 1lıman ormanların genel bir karakteristiğidir. Çalışma alanına yakın diğer floristik araştırmalar incelendiğinde, Karaköse ve Terzioğlu [15] hariç, bitki taksonlarının hayat formlarına dair bir bilgi tespit edilememiştir. Karaköse ve Terzioğlu [15]'da ise, bu çalışmada olduğu gibi, Hemicryptophyte ve Phanerophytelerin baskınlığı söz konusudur. Bu durum her iki çalışmanın da Öksin 
provenste yapılmasından ve yine benzer şekilde üç farklı iklimin etkisinin bulunmasından kaynaklanmaktadır. Dolayısı ile bu sonuç, sıralamayı oluşturan her iki çalışma alanında yayılış yapan taksonların Karadeniz öncesi dağ ve üst-Akdeniz vejetasyon katlarına olan uyumlarının bir göstergesidir. Diğer yandan Küre Dağları'nın Bartın bölümünde yapılan bir çalışmada [37] ise Hemicryptophyte ve Therophyte karakterde taksonlar ilk iki sırayı almıştır. Çalışmada bu sonucun çıkmasında temel neden olarak Tunçkol ve Aksoy [37]'un gerçekleştirdiği çalışmanın bir bölümünün sahil kısmında yer alması nedeniyle Akdenizli ekosistemlerin daha yoğun hissedilmesi ve daha fazla antropojenik etkinin bulunması olarak sıralanabilir. Diğer yandan çalışma alanında 3. sırada ise Cryptophyte karaktere sahip bitki taksonları yayılış yapmaktadır. Bunun nedenini ise Kızılcasu OPB'nde etkisini gösteren okyanusal iklimin dolayısı ile yıllık yağış miktarının fazla oluşunun bir göstergesidir [38]. Nitekim, Quézel vd. [13], Kastamonu ilinde yaptıkları çalışmada okyanusal iklimin hâkim olduğu alanlarda Fagetalia sylvaticae ordosuna ait Galium odoratum, Cardamine impatiens, Clinopodium grandiflorum, Dryopteris filix-mas gibi mesofil bitkilerin varlığında bir artış olduğunu belirtmişlerdir. Çalışma alanında Cryptophyte'lerden sonra Therophyte'ler gelmektedir. Bilindiği gibi Therophyte'ler yüksek 1şık ihtiyacına sahip bitki taksonlarıdır. Genellikle Akdenizli ekosistemlerin varlığında [39] ya da yoğun antropojenik (ormancılık, tarım, hayvancılık vb.) etkilerin varlığı miktarı ve çeşitlilikleri artmaktadır [38, 40]. Çalışma alanında her ne kadar üst-Akdeniz ikliminin etkisi bulunsa da orman varlığının yüksek olması nedeni ile örtüş değerinin yüksek olması orman altı tabakasının daha çok gölge seven bitki taksonlardan oluşmasına olanak sağlamıştır. Benzer şekilde planlama birimi içerisinde Chamaephyte'lerin oranı da Therophyte'ler gibi düşük kalmıştır. Bunun nedeni ise Chamaephyte'ler ekstrem iklim tiplerinin yaşandığı alpin gibi vejetasyon kuşaklarında yayılış yapmaktadir [30].

Sonuç olarak Kızılcasu OPB içerisinde yayılış yapan bitki taksonlarının incelenmesi ile inceleme alanının Euxine provens [28, 29] ile uyumlu olduğu, bununla birlikte Raunkiaer [27]'ün oluşturduğu orta yükseltide yaprağını döken (iğne yapraklı ormanları da içeren) 1lıman ormanların bulunduğu Hemicryptophytik yapıda [30] bir iklimin varlığına sahip olduğu anlaşılmıştır. Araştırma sonucu elde edilen bitkisel kaynaklardan oluşan veritabanı Kızılcasu OPB'nin 20 yıllık planlanmasında altlık veri olarak kullanılmıştır. Ayrıca buradan elde edilen veriler yeni Resimli Türkiye Florası'na katkı sağlayacaktır.

TEȘEKKÜR: Bu çalışma Uluslararası Ekoloji 2018 Sempozyumu'nda “sözlü-özet” bildiri şeklinde sunulmuştur. Çalışma kapsamında yardımlarından dolayı Trabzon orman amenajman heyetine ve Kastamonu Orman Bölge Müdürlüğüne teşekkür ederim.

\section{KAYNAKLAR}

[1] N. Özhatay, Ş. Kültür, and B. Gürdal, "Check-list of additional taxa to the Supplement Flora of Turkey VI," Journal of the Faculty of Pharmacy of Istanbul University, vol. 43, no. 1, pp. 33-83, 2013.

[2] N. Özhatay, Ş. Kültür, and B. Gürdal, "Check-list of additional taxa to the Supplement Flora of Turkey VII," Journal of the Faculty of Pharmacy of Istanbul University, vol. 45, no. 1, pp. 61-86, 2015.

[3] N. Özhatay, Ş. Kültür, and B. Gürdal, "Check-list of additional taxa to the supplement flora of Turkey VIII," Journal of the Faculty of Pharmacy of Istanbul University, vol. 47, no. 1, pp. 31-47, 2017.

[4] N. Özhatay, Ş. Kültür, and B. Gürdal, "Check-list of additional taxa to the supplement flora of Turkey IX," Journal of the Faculty of Pharmacy of Istanbul University, vol. 49, no. 2, pp. 105-120, 2019. 
[5] A. Güner, S. Aslan, T. Ekim, M. Vural, ve M. T. Babaç, Türkiye Bitkileri Listesi (Damarlı Bitkiler), İstanbul, Türkiye: ANG Vakfı, 2012, ss. 1290.

[6] M. Karaköse, "Numerical classification and ordination of Esenli (Giresun) forest vegetation," Biologia, vol. 74, no. 11, pp. 1441-1453, 2019.

[7] S. Terzioğlu, E. Bilgili, ve M. Karaköse, Türkiye Ormanlarl (Forests of Turkey), Ankara, Türkiye: Orman Genel Müdürlüğü, Orman Genel Müdürlüğü Dış ilişkiler, Eğitim ve Araştırma Dairesi Başkanlığı, 2012, ss. 98.

[8] H. Mayer ve H. Aksoy, Türkiye Ormanlarl (Wälder der Türkei), Bolu, Türkiye: Batı Öksin Ormanc1lık Araştırma Enstitüsü Müdürlügü̈, 1998, ss. 291.

[9] F. Yaltırık ve A. Efe, Otsu Bitkiler Sistematiği, II. Baskı, İstanbul, Türkiye: İstanbul Üniversitesi Orman Fakültesi Yayınları, 1996, ss. 512.

[10] Y. Akman, Türkiye Orman Vejetasyonu, Ankara, Türkiye: Ankara Üniversitesi Fen Fakültesi, 1995, ss. 450.

[11] P. H. Davis, P. C. Harper, and I. C. Hedge, Plant life of south-west Asia, Edinburgh, England: Royal Botanic Garden, Arboretum Row, 1971, pp. 335.

[12] Y. Akman, İklim ve Biyoiklim: Biyoiklim metodlarl ve Türkiye iklimleri, Ankara, Türkiye: Palme Yayınları, 2011, ss. 345.

[13] P. Quézel, M. Barbero, and Y. Akman, "Contribution à l'étude de la végétation forestière d'Anatolie septentrionale", Phytocoenologia, vol. 8, no. 3-4, pp. 365-519, 1980.

[14] N. Özhatay, A. Byfield, ve S. Atay, Türkiye'nin önemli bitki alanlari [Important plant areas in Turkey], İstanbul, Türkiye: WWF Türkiye, 2003, ss. 88.

[15] M. Karaköse and S. Terzioğlu, "Flora and botanic tourism potential of Yaralıöz (Kastamonu) Education and Observation Forest," Kastamonu Üniversitesi Orman Fakültesi Dergisi, vol. 19, no. 1, pp. 116-136, 2019.

[16] G. Tuttu, A. Gökhan, ve Ş. Yıldırımlı, "Tosya (Kastamonu) İlçesinin Endemik ve Nadir Bitkileri," Journal of Anatolian Environmental and Animal Sciences, c. 4, s. 1, ss. 48-52, 2019.

[17] M. D. Özen, M. U. Özbek, and M. Vural, "Flora of Armutluçayır Kastamonu/Turkey,” Biyolojik Çeşitlilik ve Koruma, vol. 6, no. 1, pp. 22-31, 2013.

[18] O. Ketenoğlu ve K. Güney, "Bat1 Küre Dağları (Kastamonu-İnebolu-Cide) Florasına Katkılar," Ot Sistematik Botanik Dergisi, c. 4, s. 2, ss. 39-60, 1997.

[19] M. Özbek ve M. Vural, "Kurtgirmez dağı ve Çatak kanyonu (Kastamonu) florası," Ot Sistematik Botanik Dergisi, c. 17, s. 1, ss. 75-112, 2010.

[20] P. H. Davis, Flora of Turkey and the East Aegean Islands, Edinburgh, England: Edinburgh University Press, 1965-1985.

[21] K. A. Baylan ve B. Ustaoğlu, "Emberger biyoiklim sınıflandırmasına göre Türkiye'de Akdeniz biyoiklim katlarının ve alt tiplerinin dağılışı," Ulusal Çevre Bilimleri Araştırma Dergisi, c. 3, s. 3, ss. 158-174, 2020. 
[22] P. H. Davis, K. Tan, and R. R. Mill, Flora of Turkey and the East Aegean Islands and Supplement I, Edinburgh, England: Edinburgh University Press, 1988, pp. 590.

[23] A. Güner, N. Özhatay, T. Ekim, and K. H. C. Başer, Flora of Turkey and the East Aegean Islands and Supplement II, Edinburgh, England: Edinburgh University Press, 2000, pp. 656.

[24] PPG I, "A community-derived classification for extant lycophytes and ferns," Journal of Systematics and Evolution, vol. 54, no. 6, pp. 563-603, 2016.

[25] M. J. Christenhusz, J. L. Reveal, A. Farjon, M. F. Gardner, R. R. Mill, and M. W. Chase, "A new classification and linear sequence of extant gymnosperms," Phytotaxa, vol. 19, no. 1, pp. 55-70, 2011.

[26] M. W. Chase, M. Christenhusz, M. Fay, J. Byng, W. S. Judd, D. Soltis, D. Mabberley, A. Sennikov, P. S. Soltis, and P. F. Stevens, "An update of the Angiosperm Phylogeny Group classification for the orders and families of flowering plants: APG IV," Botanical Journal of the Linnean Society, vol. 181, no. 1, pp. 1-20, 2016.

[27] C. Raunkiaer, The life forms of plants and statictical plant geography, Oxford, England: Clarendon Press, 1934, pp. 147.

[28] K. Browicz, "Chorology of the Euxinian and Hyrcanian element in the woody flora of Asia," Plant Systematics and Evolution, vol. 162, no. 1, pp. 305-314, 1989.

[29] M. Zohary, Geobotanical Foundations of the Middle East, Stutgart, Germany: Gustav Fischer Verlag, 1973, pp. 765.

[30] S. A. Cain, "Life-forms and phytoclimate," Bot. Rev., vol. 16, no. 1, pp. 1-32, 1950.

[31] S. P. Uzun ve S. Terzioğlu, "Sisdağ1 (Şalpazarı/Trabzon) ve Yöresinin Florası," Düzce Üniversitesi Bilim ve Teknoloji Dergisi, c. 7, s. 3, ss. 1523-1573, 2019.

[32] M. Karaköse, R. Polat, M. O. Rahman, and U. Çakılcığlu, "Traditional honey production and bee flora of Espiye, Turkey," Bangladesh Journal of Plant Taxonomy, c. 25, s. 1, ss. 79-91, 2018.

[33] E. Y. Babacan, E. Vitek, and U. Çakı1lcı̆ğlu, "Contributions to the flora of Tunceli (Turkey)," International Journal of Nature and Life Sciences, vol. 1, no. 2, pp. 39-66, 2017.

[34] M. Karaköse ve S. Terzioğlu, "Finike (Antalya) Orman Planlama Biriminin vasküler bitki florası," Kahramanmaraş Sütçü İmam Üniversitesi Tarım ve Doğa Dergisi, c. 23, s. 5, ss. 1144-1162, 2020.

[35] M. Gange and A. Ebadi, "Flora, life form and geographical distribution of plants in meyantangan mountain refuge, East Dena Protected Area, Kohkiloye and Boyerahmad Province, Iran," Journal of Applied Environmental and Biological Sciences, vol. 5, no. 9, pp. 45-52, 2015.

[36] O. W. Archibold, Ecology of world vegetation, London, England: Springer Science \& Business Media, 1995, pp. 510.

[37] B. Tunçkol ve N. Aksoy, “Küre Dağları Milli Parkı'nın florası (Bartın bölümü),” Düzce Üniversitesi Orman Fakültesi Ormancılık Dergisi, c. 14, s. 2, ss. 80-113, 2018. 
[38] E. Milani, S. Saeidi Mehrvarz, and H. Gholizadeh, "Floristic, life form and chorological studies of the Abshar protected area, Shirgah, Mazandaran Province, north of Iran," Caspian Journal of Environmental Sciences, vol. 15, no. 2, pp. 165-180, 2017.

[39] M. Barbero, G. Bonin, R. Loisel, and P. Quézel, "Changes and disturbances of forest ecosystems caused by human activities in the western part of the Mediterranean basin," Vegetatio, vol. 87, no. 2, pp. 151-173, 1990.

[40] A. Naqinezhad, H. Zare-Maivan, and H. Gholizadeh, "A floristic survey of the Hyrcanian forests in Northern Iran, using two lowland-mountain transects," Journal of Forestry Research, vol. 26, no. 1, pp. 187-199, 2015. 